\title{
A Corpus-based Analysis of the Adjective Collocates of "Sorry" in Different Genres
}

\author{
Mahdar, Universitas Airlangga
}

\begin{abstract}
Sorry is commonly used to express apology to restore social relational agreement after the offense is committed (Deutschmann, 2003). The functions of sorry are easily recognized but it is difficult to identify what or whom the word sorry is uttered for. It is important to know the purpose why the speaker utters sorry after doing something mistake. The purpose of sorry might be recognized easily if the adjective collocates of sorry is explicitly mentioned. This study aims to analyze the adjective collocates of sorry through Corpus of Contemporary American English (COCA), and to classify the similar semantic categories of the adjective collocates of sorry through WordNet. This study is analyzed based on descriptive-qualitative research design. Kwary and Arum (2011) stated that corpus linguistic research needs to be interpreted more with qualitative considerations. The data are collected by using corpus-based approach, Corpus of Contemporary American English (COCA), and classified by using WordNet application. The result provides the word sorry is found in each genre of COCA. The word sorry is mostly followed by the objects related to the semantic category time and event in academic, related to relative in fiction, related to abstract entity in spoken, related to the physical entity in magazine, and related to event in newspaper.
\end{abstract}

Keywords: collocates; corpus of contemporary American English (COCA); sorry; WordNet

\section{Introduction}

Sorry is commonly used to express apology to restore social relational agreement after the offense is committed. The intrinsic sense of sorry as a term of apology is for "claiming personal responsibility for repair-related trouble" (Robinson, 2007). The word sorry might also be used as signaling to check understanding, correcting errors, searching for words, acknowledging mistakes or potential misunderstanding, disagreement, or new important information (Yang \& Zhang, 2017).

The functions of sorry are easily recognized but it is difficult to identify what or whom the word sorry is uttered for. It is important to know the purpose why the speaker utters sorry after doing something mistake. For example, there is a young man doing something mistake to a young girl. The man accidentally stepped on the girl's foot. Then the man utters sorry without giving more explanation. It is clear enough he apologizes for his mistake. Otherwise, there is a man directly say sorry when he passes in front of a girl. The girl probably has many interpretations whether the man did mistake or will make mistake for her. It might occur because the man does not mention his purpose in uttering sorry.

The purpose of sorry might be recognized easily if the adjective collocates of sorry is explicitly mentioned. The use of sorry with the clear adjective collocates can be seen in The Corpus of Contemporary American English (COCA) whose word list used in spoken, newspaper, academic, fiction and magazine. COCA is available online since 2008, and is the largest free English corpus. Davies (2009, in Xu Yusu, 2014) states COCA has significant advantages over other free corpora in terms of vocabulary study.

There have been three previous studies attempted to discuss the word sorry. The first is conducted by Sara Lynch (2013) explores the variations of the word sorry as part of Irish English discourse. The study shows that sorry in Irish English does not only function as an apology, but identifies ten different functions including as a discourse marker, a request or to demonstrate a hearing offence. The results demonstrate that females use the token more than males. It is more inclined to be used in informal conversation than formal. The word sorry tends to be used by the younger and older 
age categories rather than the middle-aged categories, and self-identified Christians appear to use the token more than those who do not identify as Christian.

The second previous studies is conducted Barr and Gillberry (2010) explore how and when Canadians say the word sorry and how this differs between age groups and from other nationalities. This paper found that Canadians would make more use of the word sorry to avert or alleviate a problem than other nationalities. Those aged 18-25 were found to use the word sorry more frequently and in different scenarios. In comparison to those in the 26 and older category, the 18-25 year olds were more likely to use the word sorry when they were not the one at fault. It is used to keep the relationship positive. Then, the word sorry is also seemed to be used to express the idea "Please disregard what I've done," which holds less concern for the other person than apologizing and taking the blame by saying sorry or "I regret what I did. Could you please forgive me?"

The third previous study is conducted by Yang and Zhang (2017) examines different functions of the apology-based term, sorry, in language-based classrooms using the methodology of conversational analysis. Our findings suggest that sorry can perform a dual function in interaction between learners and tutors in L2 classrooms. For L2 adult learners, sorry is used as a strategy to obtain opportunities for their L2 learning during classroom interaction. At the same time, it could be adopted to claim personal responsibility for troubles caused during the learning process.

The three previous studies explained above have different purpose. The first study aims to explore the variations of the word sorry as part of Irish English discourse. The second study aims to explore how and when Canadians say the word sorry and how this differs between age groups and from other nationalities. The third study aims to examine different functions of the apology-based term, sorry, in language-based classrooms using the methodology of conversational analysis.

From the three purposes above, there is no one having purpose to identify the adjective collocates of sorry through COCA, and to classify the objects related to similar semantic meaning through WordNet application. Therefore, this study aims to analyze the adjective collocates of sorry through COCA, and to classify the adjective collocates of sorry related to similar semantic meaning through WordNet.

\section{Method}

Since this study aims to analyze the adjective collocates of sorry through Corpus of Contemporary American English (COCA), this study is analyzed based on descriptive-qualitative research design. Kwary and Arum (2011) stated that corpus linguistic research needs to be interpreted more with qualitative considerations.

The data are collected by using corpus-based approach, Corpus of Contemporary American English (COCA), and classified by using WordNet application. WordNet is a large lexical database of English. Nouns, verbs, adjectives and adverbs are grouped into sets of cognitive synonyms (synsets), each expressing a distinct concept. Synsets are interlinked by means of conceptual-semantic and lexical relations (IGI global, 2018).

The adjective collocates of sorry about appear in all genres of Corpus of Contemporary American English (COCA) are categorized as data. There are several procedures to collect the data completely. The first, the researcher opens access Corpus of Contemporary American English (COCA). The second is to choose search. The third is to select collocates. The fourth is to type the word SORRY about in word/phrase column. The fifth is to select noun.ALL in collocates list. The sixth is to select three collocations follow. The seventh is to select sections. The eighth is to choose each genre such as academic, fiction, spoken, magazine and newspaper. The ninth is to select find collocates. The tenth is to capture the adjective collocates found in each genre through Snipping Tool. The Snipping Tool is a screenshot utility included in Windows Vista and later versions that can take screenshots in a variety of ways. 
After doing data collection completely in COCA, The adjective collocates of sorry about is classified into similar semantic categories through checking in WordNet application. There are some procedures to classify the similar semantic categories. The first is to open application downloaded. The second is to type a word searched in search word column. The third is to search the noun hypernym of the word. By using hypernym, the adjective collocates of sorry can be classified in some semantic categories. The data are analyzed and interpreted descriptively. After doing analysis and interpretation, the researcher takes conclusion from the result of data collection, data classification and data analysis.

\section{Discussion}

There are five genres in Corpus of Contemporary American English (COCA) become source of data. The five genre are spoken, fiction, magazine, newspaper, and academic. The data of the adjective collocates of sorry about from each genre of COCA are classified semantic categories. There are seventeen semantic categories of WordNet used to classify the adjective collocates of sorry, they are age, animate entity, association, body, food, beverage, physical process, emotion, physical entity, event, space, pronoun, relative, condition, sound, time, and abstract entity. See the following discussions:

In spoken, the sixty-three adjective collocates of sorry are classified into nine semantic categories; animate entity (i.e., people), beverage (i.e., tea), physical process (i.e., move), physical entity (i.e., pen), event (i.e., death), relative (i.e., father), condition (i.e., pain), time (i.e., night), and abstract entity (i.e., fact). The most semantic category influence the use of sorry is the abstract entity. It indicates speakers utter sorry for abstract entity. It means that the word sorry used to apologize for something that does not appear physically.

In fiction, the hundred adjective collocates of sorry are classified into fifteen semantic categories. They are animate entity (i.e., dog), association (i.e., friend), body (i.e., hand), food (i.e., dinner), beverage (i.e., drink), physical process (i.e., crying), emotion (i.e., cunt), physical entity (i.e., car), event (i.e., accident), space (i.e., crack), relative (i.e., mother) condition (i.e., inconvenience), sound (i.e., noise), time (i.e., night), and abstract entity (i.e., way). From the various semantic categories found, it indicates the word sorry is commonly used in various purposes and it often used for apologizing relatives.

In magazine, the twenty-four adjective collocates of sorry are classified into ten semantic categories. They are animate entity (i.e., turkey), food (i.e., meat), beverage (i.e., milk), physical process (i.e., rain), physical entity (i.e., phone), event (i.e., election), relative (i.e., father), condition (i.e., condition), time (i.e., wait), and abstract entity (i.e., pun). From the various semantic categories found, the word sorry is commonly used to apology for physical entity.

In newspaper, the seventeen adjective collocates of sorry are classified into seven semantic categories. They are animate entity (i.e., girl), emotion (i.e., feeling), physical entity (i.e., wall), event (i.e., wedding), relative (i.e., dad), condition (i.e., problem), abstract entity (i.e., oversight). The use of sorry is often used to apologize for the events. The abstract entity becomes second semantic category makes people use the word sorry.

In academic, the six adjective collocates are classified into four semantic categories based on WordNet categories. They are time (i.e., delay), event (i.e., death), association (i.e., couple), and pronoun (i.e., it). The word sorry is dominantly used to apologize for time, and event.

\section{Conclusion}

This study aims to analyze the adjective collocates of sorry through COCA, and to classify the adjective collocates of sorry through WordNet. The result of this study reveals that the word sorry is found in each five genres of COCA. All genres of COCA show the adjective collocates from the word sorry. The adjective collocates of sorry is most commonly found in fiction. In academic, the 
word sorry is mostly followed by the objects related to the semantic category time and event. In fiction, the word sorry is mostly followed by the objects related to the semantic category relative. In spoken, the word sorry is mostly followed by the objects related to the semantic category abstract entity. In magazine, the word sorry is mostly followed by the objects related to the semantic category physical entity. In newspaper, the word sorry is mostly followed by the objects related to the semantic category event.

\section{References}

Barr, C. \& Gillberry, J. 2010. "Sorry . . I'm Canadian" an analysis of when Canadians use the word "sorry". Strathy Undergraduate Working Papers on Canadian English, 8, 31-39.

Corpus of Contemporary American English. Available at http://corpus.byu.edu/coca/. (Accessed 7 June 2018).

Deutschmann, M. 2003. Apologising in British English. Umea Universitet. Tryckt av Print and Media.

IGI Global Dissiminator of Knowledge. Available at https://www.igiglobal.com/dictionary/ontology-based-multimodal-language-learning/32725. (Accessed 7 June 2018).

Kwary, D. A., \& Arum, K. A. 2011. 'Lincoln's vs. Obama's presidences: A diachronic corpus based analysis of the adjectival collocates of [man] and [woman] in the American English'. ReVel, 9(17), 211-225.

Lynch, S. 2013. A corpus based analysis of the presence of sorry in Irish English discourse. Thesis. University College Dublin, Dublin, Irlandia.

Merriam-Webster Online Dictionary. Available at https://www.merriamwebster.com/dictionary/sorry. (Accessed 6 June 2018).

Robinson, J. D. 2007. Managing trouble responsibility and relationships during conversational repair. Communication Monographs, 73(2), 137-161.

$\mathrm{Xu}$ Yusu. 2014. On the application of corpus of contemporary American English in vocabulary instruction. International Education Studies, 7(8), 68-73.

Yang, R. \& Zhang, X. 2017. Sorry used by L2 adult learner: Managing learning opportunity and interpersonal relationship in classroom interaction. International Journal of English Linguistics, 8(2), 48-55. 